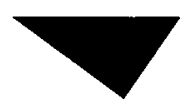

\title{
O olhar etnográfico e a pesquisa em comunicação: o trabalho de campo, as clínicas evocativas e os fluxos cognitivos
}

\author{
Julio Cesar de Tavares ${ }^{*}$ \\ Universidade Federal Fluminense
}

Resumo: A etmografia tem sido considerada uma importante

ferramenta e'm varias áreas de pesquisa. Os estudos en commicagaio deveriam utilizar esta metodologia, mais frequentenente, e com ela, abrir novas possibilidades analíticas na investigação dos fenomenos que mediam os processos culturais. Com este artigo, en procaro mostrar, etnograficamente, a imprentância de vivenciar, conscicontemente, a cxperiência do trabalho de campo e nela pereber' a forca das mediacóes e das descobertas. tais como, olugar do pesquisador diante de sua experiencia no trabalho de pesquisa, os processos mentais de engajamento do pesquisador e as articularoues entre os processos simbólicos e os conesionistas com a realidade do (ampo.
Abstract: Ethnography has been considered as a very importan lool in many research areas: Communication studies could use this methodology to chlarge the analytical possibilities that come from investigations of phenomena that mediate cultural processes. In this article, I show', based on $m$. ethnographic experience, the importance of doing ficldwork that conscionsty perceives the forces that mediate the researcher's findings: including the researderers place risai-ris his/her experience in the research work, the mental processes of the researcher's engagement and the articulations between the simbolic and comnectionist processses with the reality of ficldreseardh.

\footnotetext{
*Proficssor do Dep de Com. Social da UFF, PhD em Antropologia pela Universidade do Texas. Austin e Rock feller Resident Fellow 2000)-2001 no Center for Black Music Rescarch. Chicitgo. EUA.
} 
No atual cenário do pensamento cultural e científico, comunicação reemerge menos como conceito e mais como um princípio organizador do conhecimento e da lógica da vida. Resulta, daí, a defesa do fenômeno comunicacional como parte integrante da ontogênese de toda inteligência (natural e artificial) e todo ser vivo, além de símbolo maior da nossa presença no mundo, pois, que, todas as coisas e entes existem em função da comunicação, e, nada, sem ela, existiria (Hauser, 1998). Essa articulação torna a visão do fenômeno comunicacional um ente promotor da existência e, que, por isso, só pode ser capturado por um feixe de abordagens multiteóricas e pan-disciplinares. Todavia, a despeito da defesa da natureza multipla e heteróclita do campo dos estudos da comunicação, muito pouco se discute sobre as técnicas, metodologias e posturas nas pesquisas em comunicação, residindo, aí, uma certa limitação em relação as metodologias de pesquisas existentes ${ }^{1}$. Por isso, nesta oportunidade, interessa-me contribuir para o corrente debate em Comunicação, ao discutir os aspectos metodológicos da atividade de pesquisa em comunicação, em especial, aqueles métodos desenvolvidos a partir do trabalho de campo e enfocados através de relato etnográfico; interesso-me, sobretudo, em ressaltar os problemas relativos à natureza subjetiva que envolvem o pesquisador, à produção de objetividades, à consciência e ao 'fazer' etnografia. Neste caso, a garantia do entrelaçamento do contexto da pesquisa e o seu alvo de investigação com o investigador, se revelariam na trama que o observador media, através de sua ação como pesquisador, e, por conseguinte, através de o ambiente comunicativo, o objeto e o contexto da pesquisa que se criam e se alimentam da constituição desta transmidiação. Deste modo, o que segue é o evento-cena que é evocado no relato etnográfico por intermédio de uma conexão narrativa que procuraa representar aquela tessitura de situações; relato que transforma em texto a experiência de observar e de vivenciar formas de vida (práticas e eventos culturais), os jogos de linguagem nelas emaranhados (seus sentidos, referências, códigos e inferências) e, por extensão, o respectivo contexto e o processo de descoberta.

$\mathrm{Na}$ pesquisa dos fenômenos da comunicação, a atitude que interroga-observa o modo pelo qual inferimos (e usamos) os materiais com os quais comunicamos integra o rol dos ingredientes que o pesquisador utiliza para a identificação dos processos de produção e recepção das mensagens. Dito de outro modo, na análise dos processos, meios e técnicas comunicacionais (seja sob o ponto de vista da comunicação interpessoal ou social), o lugar que o pesquisador ocupa e o modo pelo qual ele se posiciona no trabalho de investigação, 
ambos, deveriam fazer parte do conjunto de materiais relevantes na pesquisa em comunicação. Assim como, na constituição de seu corpus, a comunicação incorporou e, se mantém incorporando contribuições teóricas, com as mais diversas origens, também a etnografia, como técnica (ou metodologia) de investigação, deveria ser tomada de empréstimo da empresa antropologica, de onde evoluiu, desde Bronislaw Malinowsky (1961), como instrumento de pesquisa.

Etnografia, assim defendida, deve ser considerada uma técnica narrativa com a finalidade de inscrever em texto, a experiência e a observação adquiridas através do convivio direto com o ambiente comunicativo/contexto cultural que se investiga,bem como através. do distanciamento da vivência originária. É este estranhamento que permite a formação do contexto psíquico do observador (Tyler 1986, Geertz 1988).

A atividade etnográfica exige, acima de tudo, que o observador exponencialize a sua capacidade perceptiva, fato que transforma o trabalho, em algo, extremamente, exaustivo, (visivelmente demonstrável no stress que segue às intervenções no campo de pesquisa, como nas entrevistas, observações, arquivos, etc.). Devido a esta exigência, o texto etnográfico resulta em permanente construção, onde, sobretudo, a atenção, a memória, a criatividade, a emoção e o compromisso que marcam o experienciado (visualizado) constituem-se em elementos fundamentais desta operação.

\section{O trabalho de campo como clínica psico-cultural: buscar o 'Outro' e re-conhecer o 'Mesmo'.}

A experiência etnográfica, restringiu-se, no meu caso particular, em inscrever em texto, as formas comunicativas identificadas no cotidiano de comunidades da diaspora africana. Ao me lançar nesta busca almejava compreender o processo de comunicação, as estruturas sociais cotidianas e as performances dos sujeitos-agentes naquelas comunidades. Adotei como caminho privilegiar os gestos, os movimentos corporais, a relação dos objetos com o corpo, a força do corpo sobre a imagem, vis-a-vis a imagem que o corpo dos sujeitos projeta no contexto, em sua dinâmica autopoética, como caminhos selecionados no intrincado jogo de linguagens não-verbais.

$\mathrm{Na}$ execução do projeto, estabeleci um firme compromisso em desenvolver duas tarefas: primeiro, estabelecer, como foco orgânico no trabalho, as formas de afetos (ativos e reativos) e os movimento corporais; segundo, examinar as minhas próprias respostas e reações aos acontecimentos previsíveis e imprevisíveis no campo, atitude 
que condicionou a minha atividade, de tal maneira a transformá-la em um tipo específico de clínica. Emprego, aqui, o têrmo clínica, no sentido atribuído por Geertz (1988), para enfatizar as demandas que constituem e produzem a experiência do trabalho de campo: objetivas subjetividades. Foi com esta atitude na clinica de minha experiência, que nasceram dois tipos de estados mentais: a intuição (sincronicidade) e a epifania. Estes dois estados da mente percorreram minhas atitudes e reflexões sem que uma agenda clara e definida orientasse os pensamentos, apesar esforço do antropólogo, que em nome da objetividade, busca padrões e invariantes daquela experiência. Tais procedimentos mentais, conforme mencionei, se entrelaçaram aos meus pensamentos para dirigir uma cadeia de fatos e acontecimentos que circunscrevem em rede a realidade em exame. Assim, não me restou outra saída, senão, perseguir o fluir dos eventos.

E, assim o fiz; ao me deslocar para Nova York, e lá residir por um período de tempo que me permitia compreender melhor o fenômeno da comunicação e experimentar o olhar etnográfico. Nesta experiência, fui norteado por dois grandes motivos. O primeiro, baseja-se na crença de que a presença negra africana no Ocidente deu origem à uma comunidade imaginária, a diaspora africana, determinada, entre outros motivos, mas, sobretudo, pela revolução comercial promovida pela troca intercontinetal de mercadorias, em especial, especiarias e mão-de-obra escrava, desde o século XV. Porisso, os sinais e traços das heranças dos africanos na diáspora civilizacional foram, cognitivamente, ordenados como cruciais componentes nos processos comunicativos, ou por força das práticas culturais performáticas ou por força da própria representação social. Não que os traços e sinais desse sistema sócio-semiótico sejam subprodutos essencialistas de natureza biológica e racial. Contrariamente, o antigo sistema colonial, aparece como que regido por uma energia que amalgama a força dos legados culturais com a aprendizagem do viver por novos caminhos no Novo Mundo; amálgama, que, todavia, gera um sistema de jogos de linguagens não-verbais que marca, tonifica e opera como narrador das experiências coletivas da diáspora africana; estas linguagens não-verbais, configuradas através do corpo (gestos e movimentos expressivos), objetos, imagens e sons, se transformaram em máquinas cognitivas e reforçaram o conceito de narrativa como o melhor veículo de aprendizagem entre os humanos. $\mathrm{E}$, é neste contexto, que as rotas comerciais que penetraram o Novo Mundo, se somaram às raízes ancestrais para, assim, definir a heteróclita cultura da diáspora africana. 
Em segundo lugar, uma outra crença também me impulsiona: a fenomenologia, com a qual compartilho o argumento que sustenta a idéia que, tanto o ponto de partida, como o destino de todo invidivíduo no mundo são determinados, de um lado, por sua corporalidade, entendida como a constituição conjuntiva de natureza bio-psiquico-cultural e, por outro lado, por sua socialidade, isto é, a capacidade de produção de linguagem, símbolos e instituições para uso coletivo e compartilhados na esfera publica². É este compartilhamento do conhecimento que define os campos intersubjetivos de um grupo e, re-enquadra, a concepção do mundo e a linguagem, como partes integrantes da identidade e da estrutura social. Nas minhas pesquisas, no entanto, intuição-sincronicidadeepifania deslizaram como situacões objetivas, conforme destacarei em duas cenas-eventos, a decisão teórica de olhar para a realidade como uma coleção de planos de imanências, e submetê-los à ótica dos problemas encontrados no meu trabalho etnográfico, de maneira que pudesse demonstrar como estes planos se operacionalizam. Procurarei, abaixo, promover uma reflexĩo acerca dos procedimentos que nortearam a produção do material de pesquisa produzido durante os nove meses de convívio com os moradores do Harlem, o histórico bairro-cidade-negro-latino, no periodo de Julho-Agosto de 1995 e Fevereiro-Setembro de 1997, em Nova York.

Evento-Cena 1 - Do modo afroamericano ('bopping') de andar: notas a respeito da cultura-fisiológica como atividade cognitiva

Ainda à procura de um caminho por onde eu pudesse começar o meu trabalho, decidi perambular pela Broadway, numa daquelas tardes invernais de Nova York, quando o vento sopra como que lançando cortantes línguas afiadas, sob um céu cor -de-chumbo, com a luz diurna em extinsão, quando ainda não são três horas da tarde. Foi nesta caminhada que, nas proximidades da estação 72 a. do Metrô, repentinamente, eu avistei um jovem negro, que, aproximadamente. deveria ter em torno de 27 anos, 1,70 de altura, 78 quilos, caminhando em direção àquela estação. Aquele negro, com aquela pele bem pretinha, como se forrado de veludo estivesse, lembrou-me, imediatamente, 'Luminoso, o tinta-forte' - conforme o chamávamos - o carismático líder de minha turma de infância no subúrbio de Ramos. quando aos nove anos de idade, ainda quando gozava do privilégio de não distinguir sonho de realidade. Incrível, pensei naquele momento, quem diria que, aqui, caminhando na Brodway, pudesse encontrar 'um outro' que iluminasse a imagem de 'Luminoso', há qua- 
renta anos empoeirada na gaveta de minhas memórias. E o mais incrível, foi a imensurável velocidade com que aquele negro pedestre da Broadway trouxe-me, por um processo de inferência, a lembrança que nem eu mesmo pensava ou sabia da existência dela. Da mesma forma que os processos hiper-velozes de nossa máquina cognitiva nos permite reavivar a memória, também, em frações de segundos, decidimos tomar decisões; e, foi o que eu fiz. Embora estivesse me dirigindo na direção contrária, o forte sotaque corporal da figura me fez com que eu alterasse o trajeto da minha caminhada e, cuidadosamente, passasse a observar com atenção os seus movimentos de locomoção, os seus gestos, a sua rítmica corporal. Quanto mais eu o observava, mais atentamente percebia que o seu modo de andar comunicava alguma coisa não-verbal e inconsciente, fato que me empurrava, cada vez mais, em direção à uma observação mais densa em torno daquele jovem. Ao decidir segui-lo, para manter uma constante e consistente observação, entrei na estação 72a. do Metro, como ele também fizera, e, sempre atento para observar sem que fosse observado. Adentro a plataforma e identifico um lugar para sentar-me; caminho na direção do espaço que existe naquele banco onde outras duas pessoas já se encontravam; ao fazê-lo, assegurava a possibilidade de continuar a leitura do livro de David Amstrong, enquanto aguardava o trem numero 2 em direção ao Centro. Minutos depois, o trem se aproxima, ritmicamente, do mesmo modo que Duke Wellington descrevera em musica,na maravilhosa 'sinfonia jazzística', entitulada "Take the A Train"3. Ouvi aquele estridente e interminável ruído agudo, que, como um punhal, rasga a pesada atmosfera subterrânea do metrô; era o ar descomprimindo e liberando as portas de acesso; preparo-me para entrar no trem. Simultanemente, todas as pessoas que se encontravam na plataforma, maquinalmente, realizam o mesmo movimento e, prontamente, se aproximam da faixa amarela que indica a zona de perigo na platafor$\mathrm{ma}$; agora, todos encontram-se prontos para se acotovelar e forçar, como um aríete, o caminho contrário àqueles que deixavam e os que congestionavam a porta do vagão. Após aqueles típicos vai-e-vem e algumas idas e vindas, finalmente, consegui entrar no vagão. Do lado de dentro, consigo avistar algumas pessoas que, em vão, ainda tentam ingressar no trem, agora quase lotado; do lado de fora, várias pessoas se apressam para manter a porta aberta, e, com este gesto, facilitar a entrada de algumas outras pessoas; o trem parte. Embora, já com todos os lugares tomados, o trem não se encontra completamente cheio. Recomeço, então, o meu exercício de observação. Sob $o$ alcance de minha visão, o jovem-negro ainda permanecia com o 
seu sólido sotaque no andar, mesmo ao se locomover no trem em movimetno. Minha persistência em observá-lo advinha da tentativa de extrair alguma informação que me revelasse alguma coisa, sob um aspecto diferente, sobre 'as maneiras de andar'. Permaneço próximo da porta traseira, no mesmo vagão onde ele se encontra, e vejo que ele conquistou uma posição melhor que a minha. Preocupo-me em camuflar o meu olhar, de modo a observar, tanto quanto fosse necessário os passageiros no carro. Curiosamente, enquanto mantenho minha posição, duas jovens negras também observam, persistente e sutilmente, o alvo de meus olhares, dividindo comigo o alvo de minha secreta investigação. Esta situação surpreende-me, e me fêz. acreditar que o meu objeto de observação agora se multiplicava, pois, desde então, eu passava a observar também as moças que observavam o meu objeto de observação; restava saber se mais alguém, além do leitor, pan-opticamente, observava-nos; nestes laços emaranhados e sequenciados, multiplicavam-se, indefinidamente. cada vez mais se abrindo em um amplo horizonte de observadores de observadores. No meio desta especulativa evocação, e, em meio ao desafio da concentração para que se retivesse ao máximo o que ocorria, verifico que a jovem mais próxima de mim, pronuncia um discretíssimo comentário à respeito do rapaz, fato que quebrou, completamente, a minha atenção sobre a cadeia de procedimentos que se efetuara, no reconhecimento do jovem negro. Redireciono a minha atenção para a referida jovem, e ela, lentamente, vira a cabeça, contorce o pescoço para se tornar mais próxima da amiga, e, elegantemente, de uma maneira muito discreta, balbucia para a vizinha de banco: veis..."

"Olhe só para ele. Esse deve ser um daqueles caras terrí-

Ao ouvir o comentário, a outra mulher moveu, suavemente, a cabeça em direção à sua direita, e, como se agisse em câmara lenta, ela projetou o seu olhar, nos olhos do jovem. Satisfeita com aquela vigorosa fração de segundos, ela volta-se para a amiga com os olhos quasi-cerrados, confirmando a silenciosa cumplicidade não verbal que, a sua expressão facial, nitidamente, terminara por conter numa dose de cínico assentimento. Com a expressão facial fechada, a sua face revela uma expessão 'bicuda', com os lábios alongados como se fosse demonstrar uma expressão de insatisfação; ao mesmo tempo, ela cruza as pernas e pousa a sua mão direita sobre a sua mão esquerda que segurava-Ihe uma bolsa; olha para a amiga e, então, finalizando a construção daquilo que seria um complexo emblema corporal, 
-ali arquitetado pela sua "expressão gestual "; ela, então, ensaia um olho-a-olho com a colega, e, como que sugando os dentes, ela encerra aquela narrativa não-verbal emitindo um som bastante característi$\mathrm{co}$, que finaliza aquele gestus. Com certeza, que por mais que eu tente, jamais poderei, aqui apresentar o volume de movimentos e a carga de intencionalidades inconscientes. Em busca do significado desta expresão, obtive de uma das minhas consultoras a confirmação de que aquela expressão era bastante peculiar, especialmente, entre as mulheres negras, e que é encenada, automaticamente, em situações de aversão, desafio ou desgosto por coisas, pessoas ou contextos. Com um discreto sorriso a rubricar este modelo de conversação gestual, a resposta da outra, aparecera como uma consciente confirmação da emoção ali narrada não-verbalmente.

Essa cena, se mostrou como uma forte referência ao exame das materialidades da comunicação não-verbal. E, é inteiramente possível classificá-la como um evento-cena, já que é em situações de microfísicas dimensões de performances e representações. Entre outras que eu coletei, esta foi uma das mais poderosas situacões, devido a familiaridade que exercia para com outras práticas, atitudes, atos comuns entre negros fora da America. Talvez porque aquele evento-cena possuísse um poderoso apelo iconográfico, que faz das rotinas com aquele tipo de prática comunicativa, algo mais que significante entre os negros americanos, e os assegurava adquirir uma configuração performática, assim manifesta: o jovem com seu 'modo de andar' revelando um tal sotaque, expressava uma forma de auto-estilização (1) tinha merecido comentários de dentro da comunidade, comentários capazes de mostrar-me que ele jamais seria um marginal; (2) o ato de indicar com os lábios e a expressão de um ruido bem singular; (3) as maneiras bem performativas de movimentação lateral com a cabeça. No conjunto, estes são exemplares transatlânticos que transitam e incorporam o cotidiano dos descendentes da Diáspora Africana. Mas, porque transaltlântico, se tais caminhos de significação, adquirem, no entanto, visíveis gotas de estilo regional e pessoal, quando articulados ao perceptivo modo de andar e indicar com os lábios ? Ora, são estas variações que fornece-nos a possibilidade de pensar a respeito de 'gêneros' de incarnação ou incorporação. Eu mesmo presenciei este processo de auto-representação através do "caminhar" e do "fazer bico" no Brasil. A fala da mulher ao sugerir em tom fortemente irônico, expresso através de gestos como retorcer a boca e o nariz, e agindo como se estivessem desdenhando o rapaz. Certamente que a fala da mulher emergiu 
como uma resposta à atitude do jovem, e assim, introduziu, para mim, uma questão de gênero. A atitude do rapaz pode representar um signo masculino indexicalizado com um sentido se pertencimento 'a gang' ou algum ameaçador ou ousado comportamento auto-defensivo. Eu não penso que ele ouvira ou percebera os comentários das duas jovens, mas em todo caso, alguns minutos depois do ocorrido, ele decidiu mudar de vagão.

A cadeia de possibilidades que esta cena abriu, foi para mim algum coisa, absolutamente, interminável. Contudo, a cena apareceume, imprevisivelmente, como resultado da decisão de seguir o rapaz que havia sido identificado, observando o que era possível de acontecer, enquanto, naive e desinteressadamente, capturando tudo que representasse corpos em conexão através dos afetos e movimentos, como uma mente livre, leve e solta. E, esta imprevisíbilidade, não é uma condição paranormal, pelo contrário, pois ela existiu conscientemente para mim, bem como ela não é um evento mágico, pelo contrário, estas imprevisibilidades articulam, de fato, uma cadeia de intencionalidades presentificadas como tomada de decisão e fruto de uma sincronicidade de eventos, encapsulados pelas inferências do observador, eu-próprio, em articulação ao que fora capturado e ao que se esperava encontrar. Foi aquela imperceptível temporalidade que conduziu a minha percepção do sotaque corporal do rapaz que me fez abrir um novo portal. Aquele movimento, corresponde a uma fatia minimal de tempo, um intervalo tão pequeno quanto representativo de uma expressão qualitativa do tempo do acontecimento emocionalmente experienciado. O imprevisível e o intuído por extensão, passam a constituir um momento-movimento afetivo, cuja congruência projetou em mim um reconhecimento da articulação entre movimento e emoção.

\section{Evento-Cena 2 - Do ritmo como atividade inconsciente e cognitiva}

O mais epifânico momento, no entanto, nesta jornada ao Harlem, ocorreu-me num ensolarado domingo, em uma Igreja protestante, em Queens, um dos cinco grandes distritos que constituem a cidade de Nova York (os outros quatro são Manhattan, Staten Island, Brooklyn e 'The Bronx'). Aquele domingo começou bem cedo, e, com estranhíssimas situações ocorrendo ao meu redor. Acordei, já atrasado, às 08:00 da manhã tendo ido dormir às 04:00. A culpa foi de um grupo musical cubano que, pela primeira vez, se apresentava nos Estados Unidos. Recomendado por amigos, compareci ao "SOB's", 
a casa musical que, permanentemente, concentra a sua programação no virtuosismo rítmico da cultura afro-latina, assegurando sempre maravilhosas apresentações de rumba, salsa, merengue, samba, axémusic, etc. Levantei-me aos troncos-e-barrancos. Rapidamente, me preparei para o encontro às 09:00, quando seria apresentado ao pastor de uma Igreja, em Queens. Para não perder a carona de um dos membros da Igreja, em uma viagem de carro que levaria cêrca de 50 minutos de Manhatan, nem mesmo esperei o elevador. Desci correndo os oito andares do prédio onde residi durante todo operiodo de 1997, em frente a praça Marcus Garvey, no cruzamento da 5a. aveni-

76 da com a rua 120, o coração do Harlem tradicional. Contudo, nesta pressa alucinada, e, em meio a uma avalanche de pensamentos, descuidei-me, e, por um instante, descoordenei-me, completamente, no exato momento em que me dirigia para a parte exterior do prédio; não deu outra, cai na rua. Errara o passo e pisara fora do último degrau; o resultado foi que rasguei a calça da missa, na altura do joelho, quebrei os óculos, além de machucar o joelho. E tudo isso em uma fração de segundo. Ainda de quatro, olhei ao redor para conferir se alguém me observava-afinal, voces sabem como situações como estas são constrangedoras. Felizmente, me dei conta que ninguém testemunhara o acidente. Recuperei-me, e, ainda mancando, retorno ao meu apartamento. No caminho, inesperadamente, encontro um dos zeladores do prédio, que, prontamente, se dispôs a iniciar uma conversa à respeito do crescimento da população de ratos no edificio. Eu não o conhecia e ele agia como se já me conhecesse, fato que me fêz ouvi-lo, pacientementre; mas percebi que, devido o avançar da hora, eu teria que quebrar a conversa. "_OK, meu irmão, nós deveríamos conversar a respeito deste assunto mais tarde, se não lhe causar inconveniente. Eu estou indo para a Igreja, agora." Foi o suficente para que ele, imediatamente, tirasse as suas pesadas luvas de couro, se apresentasse e, em seguida, se despedisse. Minutos mais tarde, já estava de volta, no exato momento em que a minha carona aportava o edificio. À caminho da Igreja, sentindo-me mais seguro e tranquilo ao retomar o ritmo dos acontecimentos, em conversa com meu amigo, procurei, então, relatar a constelação de surpresas, tais como tropeções, escorregões, roupa rasgada, ferimentos, quebra-de-óculos, conversas sobre ratos, e tudo mais, durante o curto espaço de tempo, entre o meu despertar e o nosso encontro. $O$ meu amigo respondeu: "_Relaxe, cara, isto é demais para um domingo de manhã." Aliviado, eu olhei para o meu lado direito e, inacreditavelmente, vi um homem também tropeçando no meio-fio, e, caindo na calçada, quase que num re-play, do que havia aconteci- 
do comido há poucos minutos atrás. Surpreso, com o fato, eu disse para o meu amigo que dirigia: "_ Você viu aquilo ?" Ele tentou olhar através do retrovisor e respondeu: "- Nossa, aquele cara se machucou, e olhe só, ele esta tentando disfarçar." Voltando atenção para a sua dianteira, e, sutilmente dirigindo um olhar de soslaio em minha direção, completou: "_Cara, pare de atrair o diabo. Estávalmos falando do seu tropeção e agora acontece isto. Vamos mudar de assunto, caso contrário nos vamos bater com este carro".

Permanecemos calados durante toda viagem, até que finalmente, depois de quase uma hora de estrada, chegávamos em Queens. Entrei naquele Templo gigantesco e assisti à uma maravilhosa, emocionante e intensa cerimônia. Afinal, domingo é um momento unico nia comunidade negra americana, de norte a sul, da costa leste à costa oeste, onde à mesma hora, das nove às três, milhões de famílias afroamericanas se reunem para orar e acompanhar os caminhos da comunidade em um ritual repleto de ritmos, sons, e corpos em movimentos. O serviço terminou em torno de 1:00. Ao sair da Igreja, um dos fiéis veio ter comigo uma conversa, especialmente, por saber que eu era brasileiro, e que ali estava para conhecer e aprender um pouco da cultura comunitária afro-americana. Aquele senhor, que deveria ter por volta de 60 anos, introduziu um tema muito interessante, que, de certa maneira, possuia uma forte sincronicidade com os acontecimentos ocorridos naquela manhã. $O$ assunto veio imediatamente depois que tessi alguns comentários a acerca do meu estado de êxtase, ao ver aquelas pessoas, entusiasticamente, na Igreja, cantando, batendo palmas e dançando para Deus. Foi, aí, que eu trouxe à tona um comentário que existe no Brazil: "_Eu não acredito num fiel não mexa, eu não creio em um Deus que não dance". Como resposta, ele começou a falar, à cerca da importância do ritmo na comunidade afro-americana e ofereceu-me, literalmente, um dos mais fortes argumentos, até então identificado em comunidades negras em New York. Com uma incontestável simplicidade, ele segurou-me pelo cotovelo, e carinhosamente, aproximou seu corpo ao meu, e disse:

"Todos nós possuimos ritmo. Eu gosto de apreciar as pessoas andando e quando eu vejo as pessoas negras andando, devo the revelar, meu irmão, nós somos diferentes."

Ali estava uma afirmação surpreendente para mim. Mais do que a fala, proferida em sentenças, que, em si-mesma, encerram um sentido por demais óbvio, a proposição ganhara uma força extraordinária, 
perlocucionária, somente devido ao peso da relevância que aquele tema, o ritmo, adquirira para mim, no decorrer de toda minha biografia, em especial naquele domingo. Porisso, a proposição, possuia uma abrangência inimaginável e me projetava naquele instante, num novo universo. Presente naquele jogo-de-linguagem, encontrava-se formulado também uma maneira de pensar e organizar a vida e que possuia uma intensa semelhança com o que eu, até então, presenciara no Brasil também. No mesmo instante em que ouvia as palavras e os comentários daquele senhor, um jovem casal negro, elegantemente vestido, passava na calçada, bem à nossa frente. Não perdendo a oportunidade de incorporar ao que comentávamos, aquela evidência, e, como se quisesse construir emblemas metonímicos que suportassem suas idéias, o cavalheiro aponta para o casal e olha para mim, e, segurando-me afetuosamente pelo cotovelo disse-me (agregando com este gesto, confidiência, confiabilidade, e gentileza: força do inconsciente cognitivo):

"_Filho, olhe para eles, olhe para como eles se movimentam graciosamente como se estivessem dançando. É claro que eu estou falando a respeito de alguma coisa mais ampla do que o ritmo musical. Eu estou me referindo a música de Deus, o ritmo da vida, alguma coisa que faz com que os negros sejam diferentes, por conhecer esse ritmo da vida que salvou-nos do holocausto, e nos faz saber em profundidade a respeito de Deus, porque nos conhecemos o ritmo"

Após esta explanação e demonstração, eu calei e transformeime inteiramente em ouvinte. Toda e qualquer explanação possível já estava lá, incorporada na fala do interlocutor. Era como se um teorema tivesse sido resolvido naquela exposição que articulava gestos, fala, imagens, objetos, contextos, emoções, bem como a experiência do interlocutor, para quem a proposição estava comunicando; tudo estava articulado aos acontecimentos da minha arritmica manhã. Para um analista pós-moderno, esta seria uma típica fala contaminada de argumento essentialista, pois o apriorísmo da abordagem pós-moderna, não leva em conta a pragmática das proposições, e portanto não dá relevância ao seu uso, a sua função no campo do senso comum. Aquele velho senhor afirmara um ponto de vista com autoridade de quem possui olhos críticos e poéticos além de aguda habilidade para observar os eventos domésticos e os comportamentos em sua arena, permitindo-lhe extrair das banalidades da experiência cotidiana na vida comunitária, emoção e reflexão de base ontológica. Nascia, assim, ali mesmo, a minha consciência para pensar o ritmo, o que me levou a consciência da oportunidade em desen- 
volver uma análise e pesquisa sobre o ritmo. Na visão que o "veterano" membro da Igreja fazia do movimento, uma visão emocional do movimento, também introduzia uma concepção de ritmo articulada às noções como causalidade, intencionalidade e consciencia.

\section{O Olhar Etnográfico: Evocação multi-media, Sincronicidade e Epifania}

Até aqui, temos um duo de descrições que conduzem suas evidências em direção à uma cadeia de sincronicidades (ou, na linguagem de Wittgeinstein, familiaridades), que culminam em um momento de epifania. Neste caso, o que tornou-se para mim, profundamente revelador foi o fato de verificar a composição real. no interior do próprio ritmo, do lado oculto do seu vigor através da rítmical aritmia ciscardiana, constituida naquela experiência de uma ensolarada manhã de domingo.

A cadeia pragmática de situações comunicativas, que se manifestaram nas minhas des-coordenações, nos meus tropeços, nas quedas, no fortuito encontro com o zelador e sua conversa sobre ratos, na imagem de um 'desajeitado' que tropeçara quando de minha passagem, e, por fim, na minha conversa com um cavalheiro do círculo dos fiéis, da Igreja em Quecns, todo este encadeamento conectou uma possível experência teórica. No meu caso, a ação etnográfica começou, como exercício de consciência constituida por "quadruplo engajamento", onde encenam (1) o observador, (2) a açăo do observador em confronto/aliança com o seu (3)observado - o 'Outro' -e (4) o contexto, no qual, a experiência se realiza. É na transformação desta relação, observador-ação-observado-contexto, (o mesmoas ocorrências-o outro-imbiente comunicativo) $\mathrm{em}$ um único elemento, que se opera a força consciente desta imbricação e se constitui a ação etnográfica. Ação etnográfica que é impregnada pela consciência da situação, numa atitude de atenção total e cuidado absoluto com o que circunscreve o evento, através de processos que, na textualização, validem e verifiquem aquilo que torne o evento relevante. É. a partir desta ambiência que, cognitivamente, as condições do ser-estar-no-mundo se operacionalizam, naquele momento liminar, dividindo ou multiplicando a experiêncial do dia-i-dia, em diferentes camadas do passado, presente e futuro.

A prática etnográfica, assim intuída, aproxima o etnógrafo/pesquisador da consciência da cognição ecológica ou da autopoética da consciência, ao se admitir que a consciência se autoorganzia. Dirigida por fluxos de emoções, sentimentos e afecções. esta cognição ecológica, envolve a prática etnográfica e conduz o pesqui- 
sador à incorporar as aberturas e a participar com entregas no processo objetivo de produção de subjetividades e múltiplas textualidades.

Confirmam esta proposição os biólogos que investem em estudos de uma Biologia da consciência, como Humberto Maturana e Francisco Varela (budistas e biólogos chilenos e que trabalham na área das ciências cognitivas). Desenvolvem suas idéias a partir da noção de intuição e a respeito do venha ser a autopoética da fenomenologia biológica, admitem que esta repouse nas concepções de inseparabilidade de um particular modo de estar no mundo daquilo que seria o modo pelo qual o mundo aparece como sugere Spinoza que nos diz que, todo o fazer é um conhecer e todo conhecer e um modo de fazer ${ }^{4}$.

É, esta condição de inseparabilidade que verificamos na atividade etnográfica que defendemos. A ação etnográfica que acontece em ondas comunicativas, em fluxos conduzidos por um processo intuitivo, intensamente, presente. Esta atividade requisita que o etnógrafo trabalhe, permanentemente, com a emoção, a qual implica em um ato de entrega e de total recepção ao que é imperativo no trabalho de campo. Emoção que deve ser considerada e trabalhada como materialidade comunicativa, como registro de conhecimento, e, portanto, ela não é uma manifestação isolada no momento da ação etnográfica. Como a vida cotidiana é a arena onde esta operação ocorre, com este tipo de experiência, o etnógrafo transforma-se no agente da ecologia transpessoal da comunidade, experiência que vai além do que tem sido classificado, meramente, como estoque de símbolos, e, porisso, permitindo a conexão com uma inteligência cósmica, condição global do ser. Experiência que transcende as fronteiras do social, national e do cultural, e enuncia a possibilidade de uma clínica através da pragmática do trabalho de campo. O etnógrafo e/ou pesquisador, na lida do campo, trabalha, consciente ou inconscientemente, com a intuição e com a emoção, tópicos que se explorados podem resultar no desenvolvimento da consciência da dimensão orgânica do ato intelectual. Assim como os biólogos que exploram uma biologia da consciência, poderemos explorar a consciência de uma 'osmose afetiva' que ocorre durante o ato de conhecer; consciência da dimensão poética do imaginário, consciência de uma mente ecológica ou mesmo, a consciência de um pensamento orgânico, parte do processo de conhecimento. Este caminho foi pioneiramente instaurado, "etnograficamente", por Merleau-Ponty, com as suas noções e descrições das emoções corporais, sentimentos e pensamentos orgânicos, através da analitica existencial-fisiologia. 
Este posicionamento não dicotômico, e sim, participativo da mente, engaja o corpo na realidade, e aborda a sociedade como a corporificação um ambiente comunicativo ${ }^{5}$ com toda singularidade e universalidade.

Este caminho de trabalho apresentado em eventos-cenas é um projeto etnográfico de mente participativa, e que passo agora a exercitar sua reflexividade, persegue, acima de tudo, um objetivo além da prescrição disjuntiva e latidudinal da realidade, em formas objetivas e subjetivas, construindo um volume, um container metafórico; é um raciocínio bloqueado pelo edifício que o contém e que resulta na persistente redução da abordagem da realidade em formas dualistas de percepção. Neste modelo, que poderíamos ainda descrevê-lo como holístico-singular, nele, tôdas as estas possiblidades-tanto as objetivas como as subjetivas, são compreendidas como 'plateaus', que definem uma dimensão ampla e plana, e, porconseguinte, remarcam e redefinem o solo da experiência etnográfica para os argumentos que nela estão inscritos ${ }^{6}$. Trata-se de um fazer no campo que acasala os insights e os conecta às inferências sobre o que se analisa, ao invés de, somente, interpretar as simbolizações que representam os efeitos da alma e os afetos do corpo. Esta antropologia vitalista da experiência do conhecer, parte do viver e evoca temas como intuição-epifania, conforme pude rapidamente demarcar na minha própria experiência.

Muitos pesquisadores, incluindo alguns antropólogos (DavidFloyd \& Arvidson 1997), mostraram através de abordagens interdisciplinares, que intuição (sincronicidade), não trata de nenhum fenômeno paranormal nem tampouco, um tipo de espiritualização de fatos materiais ${ }^{7}$. Segundo eles, trata-se de um fenomeno físico definido como uma 'acasualidade' que conecta - e redifica - o interior ao exterior dos eventos significativos através do sentido destes mesmo eventos (Mansfield 1996). Os avanços nesta área reforçam um dos mais instáveis pontos da semiótica de Pierce, isto é, o estudo das categorias dos sistemas da primeiridade, as quais, referem-se ao sentimento, a emoção e, à condição de um "pode-ser", conforme ele próprio, colocava. Compromissada com uma reflexão consciente da atividade cognitiva, a experiência etnográfica, desta maneira, transforma-se, em uma análise ecológica, que centra-se no ambiente comunicativo, ou seja, nas coalisões e confrontos de afetos e movimentos. É este o fato novo que a ciência cognitiva, a biologia e a psicologia evolucionária nos revela nas descobertas a cerca do corpo do 
observador em comunicação nos mundos observados, do interiores para o exteriores ${ }^{8}$. Comunicação, portanto, aborda-se sob o ponto de vista ecológico, como fenômeno e ferramenta cognitiva que alavanca a nossa consciência para alertar a captura de das conexões dos múltiplos mundos que vivemos.

\section{Conclusão}

Nesta exposição eu tentei demonstrar que o trabalho de campo merece ser valorizado como um momento da consciência e que o pesquisador/etnógrafo, deve permanecer em cuidadoso alerta e aberto para ser sensibilizado por esta experiência, não como uma banalidade turística, ou, como um estupro do exótico, mas como uma intervenção performática de um semioticista-poeta-viajante no interior e entre culturas. Penso que o(a) pesquisador-etnógrafo poderia transformar-se, quando em trabalho de campo, em um(a) evocador(a) multi-mídia das possibilidades inferênciais, que possam se enquadrar com as tradução de suas experiências em textos culturais.

Um outro aspecto que eu pretendi demonstrar é que a intuição (sincronicidade) epifania são efetivas ferramentas para a comunicação ecológica do etnógrafo e que deveriam, efetivamente, ser incorporadas e desenvolvidas por pesquisadores, devido ao alto nível de atenção e consciência que, ecologicamente, operam-se através da extensão consciente de nossa subjetividade perceptiva em um determidado ambiente comunicativo. Reconhecendo o papel da intuição e da sincronicidade como fortes componentes do processo de conhecimento, esta experiência poderia abrir para os antropólogos a oportunidade de realizar uma contribuição significativa para o desenvolvimento dos estudos da consciência. A descoberta e apreciação de uma mente ecológica preparará futuro pesquisadores de campo para a compreensão holísticas e pós-humanísticas das formas globalizadas de conexões ${ }^{y}$ entre socialidades e percepções que ultrapassem as meras simbolizações do paradigma representacional.

\section{Notas}

1 É importante frisar que as metodologias linguísticas, a análise do discurso e a analítica semiótica se constituiram em sólidos modelos nas pesquisas em comunicação.

2 Assim, associo-me a pensadores que desenvolveram a crítica à linguagem na esperança que esta critica enfatizasse o re-conhecimento das intencionalidades, que, por vezes, nos permite identificar - a despeito das diferenças entre os grupos analizados - 
familias de semelhanças emergindo por toda a estrutura social. através de atos de fala, dos atos linguísticos evocados, ou ainda. por intermédio da própria relevância com que os atos comunicativos se manifestavam, sem que jamais abandonassem a sua condição corporal, mesmo quando se manifestam na condição de fenômenos mentais. Refiro-me, particularmente, à tradição ensejada pela pragmática de Wittgenstein, Mead, Ryle, filósofos que apresentaram um caminho alternativo às abordagem deterministas dos psicólogos e biólogos, e, ao mesmo tempo. contribuiram para uma guinada na compreensão dos fenômenos culturais como fatos sociais, cognitivos e comunicativos, simultaneamente. Por outro lado, existe também nesta mesma direção, uma tradição de filósofos que como Merleu-Ponty, Husserl, Ricouer, traduzem as suas experiências com a linguagem como instrumento de avanço na compreensão dos fenômenos mentais e como uma nova chave para os caminhos analíticos do cotidiano.

3 Take The A Train, Disc 1, Track 7, in Ellington At Newport. 1956 (Complete). Columbia/Legacy, February, 1999. Recorded in Performance at the American Jazz Festival at Newport, R.I., on July 7, 1956.

4 Conforme e a interpretação de Deleuze da obra de Spinoza. Podemos identificar em Baruch de Spinoza, a defesa de uma radical antropologia pragmática e filosófica, baseando-se na idéa de que o corpo e a mente são uma e a mesma coisa concatenadas em ações nas quais ambas se integram numa mesma escala, do mesmo modo que o corpo e a mente se encontram integradas. Deste modo que o ato de interagir e o ato de compreender não são capazes de existir separadamentc. As conexões destes processos, nas palavras de Spinoza, são alcançadas através dos afetos e de Deus, que é o próprio amor que reside em nós. Com esta leitura e, por este caminho, as unidades do conhecimentos não são puras proposições, e, sobretudo, atos humanos reduzidos à condição de proposições. O modelo que esta antropologia da praxis oferece entende o corpo como um conjunto de atributos formados pelos afetos e movementos, e, deste modo pressupõem que a existência de corpos, mentes e individuos repousa em um campo de imanência definido pela cinestesia e atributos afetivos.

5 Assim denomino, numa alusão ao etólogo, biólogo e semioticista Jacob von Uexkull e ao antropólogo Lucien Levy-Bruhl. O primeiro, em suas experiências pioneiras sobre biologia da consciência, desenvolveu a teoria do Umwelt, um organismo que nos cir- 
cunscreve e que é possuidor de qualidades subjetivas. Unwelt, procura significar "o universo subjetivo significante". Uexkull, caracterizou o fenômeno do Unwelt, examinando o comportamento dos animais que envelopam, em redes de signos, o ambiente que o envolve, para aumentar o sistema de auto-defesa, na medida que os sinais externos são percebidos através de significados subjetivos e acessados apenas pelos sujeitos neles codificados. Um exemplo de Unwelt estaria no sonor do morcego, que, mesmo após ser cientificamente identificado, este sonar só será decoficado, se inferido e acionado pelos equipamentos cognitivos do morcego; portanto, isto quer dizer que somente o morcego é capaz de dizer de si mesmo, pois o Unwelt é um dos componente que aciona a atividade participativa da mente com a relatividade envolvente. O segundo pensador é Levy-Bruhl, antropólogo francês que desenvolveu a idéia de relatividade cognitiva ao postular que a lógica que nós validamos em nossas descrições de mundo, não pode ser considerada como universal, mas pelo contrário, esta lógica é uma função de nossas imediatas circunstâncias tecno-ambientais, de nossas particularidades linguísticas, e de nossas heranças ideológicas, e porisso, nenhuma lógica é superior à qualquer outra. Todavia, dado à ambiguidade do seu trabalho, Levy-Bruhl fora considerado etnocêntrico. O aspecto central do seu trabalho foi edentificar que as comunidades não-ocidentais operam regras lógicas da não-contradição, sendo portanto antiaristotélicas, e porisso, possuindo regras e principios próprios que conduziam ao conhecimento, a partir da união do objeto com o conhecimento, participando com, e não em contradição com o objeto do conhecimento.

6 Em muitos outros campos de pensamentos, este caminho encontra continuidade, tanto no ocidente como no oriente, em tendências que se fortalecem no século $\mathrm{XX}$, na corrente de Wittgenstein e sua ideia de gramatica, formas de vida e jogos de linguagem; seja com George Mead - em sua filosofia da ação baseada na comunicação gestual; seja com Merleau-Ponty - e sua noção de pensamento organico, ou ainda seja, especialmente, com Deleuze, quem mais refinadamente elaborou as ideas de afectos e planos de consistencia como os pontos fortes de sua filosofia virtual.

7 Intuição sempre foi um tema recorrente nas pesquisas de comunicação interpessoal, seja de Simmel à Mafesoli, seja de Mead à Goffmann. Um tópico tratado como um fenômeno que aponta para a compreensão da realidade através da ação do que 
poderiamos denominar de razāo sensível ou a própria experiência pessoal de interferir durante as ocorrências em pesquisas de campo. Infelizmente, antropólogos raramente consideram a intutição como parte do processo de consciência e, nem tampouco, parte importante da experiencia. Contrariamente, devido ao prevalente subjetivismo do paradima antropologico, intuição tem sido considerada como uma expressão do processo de significação.

8 ver Ponty 1963; Gibson 1950, 1966, 1979; Damasio 1994

9 O uso que faço do termo conexão esta relaciona-se à concepção conexionista de construção dos processos cognitivos ou, como também é conhecido, processo de distribuição paralela. $\mathrm{O}$ uso que os filósofos da mente fazem do conexionismo, vem consolidando uma explanação das performances cognitivas, através de noções traduzidas nas idéias de redes e networks, importante metáforas para abordar o processo de construção do conhecimento e da consciência. O principal objetivo que esta modelagem do processo de conhecimento tem apresenta é uma arquitetura cognitiva que contém dois aspectos fundamentais: o controle motor e a compreensão linguística. O desafio conexionista introduz implicações de ordem epistemológicas, pois, o argumento que os conexionistas sustentam, explica cognição (ou construção do conecimento) como o resultado da estocagem de proposições e experif́ncias, que, dinamicamente se conectam com as regras lógicas, as experiências corporais e as atividas da imaginação (Dennet 1991, Clark 1989, Rumelhart et al. 1986, Rosch 1975). Desta maneira o conhecimento, acrescentam os conexionistas, não resultaria, exclusivamente, de uma manipulação de símbolos, conforme defende a visão representacional e cartesiana da sociedade. A abordagem conexionista, embora bastante multifacetada e com inúmeros posicionamentos que se extendem da filosofia analitica até a fenomenologia pontiana, estabelece um paradigma novo que entra em confronto e competição com o paradigma representacional. Numa era como a que vivemos, onde conceitos como rede e virtual invadem o nosso cotidiano, as oportunidades para este novo paradigma são, realmente, promissoras, especialmente se se consideram os grandes resultados que este modelo de pensar tem imprimido no desenvovimento da inteligência artificial e na identificação de traumas causadores de alterações em processos mentais, confome a sua aplicação nas neurociências cognitivas 


\section{Bibliografia:}

CLARK, Andy, 1989 Microcognition: Philosophy, Cognitive Science, and Parallel Distributed Processing. Cambridge, MA: MIT Press.

DAMASIO, Antonio, 1994 Descartes's, Error: emotion, reason, and the Human Brain. Agrosset/Punam Book. New York

DAVID-FLOYD \& Arvidson (ed.), 1997 Intuition; The Inside Story: Interdisciplinary Theory. Minneapolis: The University of Minnesota

DELEUZE, Gilles, 1992 Ethology: Spinoza and Us in Incorporations, pp. 628/633. Zone, New York, NY.

DENNET, D., 1991 Mother nature versus the walking encyclopedia. In Philosophy and Connectionist Theory, ed. W. Ramsey, S.P. Stich, and D.E. Rumelhart. Hillsdale, NJ: Lawrence Erlbaum

FANON, Frantz, 1967 Black Skin, White masks.trans. Charles Lam Mendonça. New York: Grove Press.

GIBSON, J.J., 1950 The Perception of the Visual World. Boston: Houghton Mifflin.

, 1966, The Senses Considered as perceptual System. Boston: Houghton Mifflin.

, 1979 The Ecological Approach to Visual Perception Hillsdale, NJ, Hillsda

GEERTZ, Clifford, 1988 Words and Lives: The Anthropologist as Author. Stanford University Press.

HAUSER, Marc D., 1998 Evolution of Communication. MIT Press, London, England.

LEVI-BRUHL, Lucien, 1923 La Mentalité Primitive in Bulletin de la Societé Framçaise de Philosophie.

MALINOWSKI, Bronislaw, 1961 Argonauts of the Western Pacific. New York: E.P. Dutton.

MANSFIELD, Victor, 1995 Synchronicity, Science, and Soul Making. Chicago: Open Court, 
MATURANA. Humberto e Francisco Varela, 1997 De Máquinas e Seres Vivos: Autopoiese, a organização dos seres vivos. Porto Alegre: Artes Médicas

MEAD, G.H., 1967 Mind, Self, and Society: From the Standpoint of a Social Behaviorist. The University of Chicago Press. Chicago

MERLEAU-PONTY, Maurice, 1962 The Phenomenology of Perception. Evanston: Northwestern University Press.

ROSH, Eleonor, 1975 Cognitive representation of semantic categories. Journal of Experimental Psychology: General, 104, 192-233.

RYLE, Gilbert, 1949 The Concept of Mind Chicago: The Univesty of Chicago Press.

RUMELHART et alli, 1986 Parallel Distrubuted Processing: Explrations in the Microstructure of cognition. Vol.: 1: Foundations. Cambridge, MA.: MIT Press.

SPINOZA, Baruch, 1986 The Ethics and on the Correction of the Understanding. London: Dent.

TYLER, Steven A., 1986 Post-Modern Ethnography: From Document of the Occult to Occult Document in Writing Culture: The Poetics and Politics of Ethnography, eds. James Clifford and George Marcus. Berkeley: University of California Press.

UEXKULL, Jacob von, 1926 Theoretical Biology, New York: Harcour, Brace \& Company, Inc. 1940 The Theory of Meaning. In Semiotica 42(1): 22-82

UEXKULL, T., 1989 Jacob von Uexkull's Umwelt-Theory. In The Semiotic Web, 1988. T.A. Sebeok \& Umiker-Sebeok (eds,). pp.129-158, Berlin, Mouton deGruyter.

WITTGENSTEIN, Ludwig (1958), 198I Philosophical Investigations. trans.: GEM.Anscombe. Oxford: Basil Blackwell.

Palavras-chave

1. Comunicação;

2. contexto;

3. experiência etnográfica

4. trabalho de campo

5. cultura afro-americana 
88 